\title{
Potential Modeling Of Pavement Deterioration Rate Due To Cracking
}

\author{
Wee, S.Y.1, R.A @ R.B Chan², Teo, H.W. ${ }^{3}$
}

\begin{abstract}
Bitumen pavements tend to crack at some point of their life under the combined action of traffic and the environment. These cracks are defects in the pavement surfacing which weakens the pavement and allows water to penetrate and cause further weakening. Once initiated, cracking usually increases in extent, severity and intensity, leading eventually to pavement failure. Cracking has therefore been an important indicator for road pavement maintenance. In view of the extensive road network in Malaysia covering more than 80,000 kilometers in total, the government has to spend huge sums of money on the repair of cracks under its annual road maintenance program. However, the resurfacing works have not always been successful and cracks tend to reappear after some time. The accurate prediction of crack occurrence and the effectiveness of resurfacing works to control cracks are key factors in predicting the timing and costs of road maintenance. In view of this, it is imperative that a suitable model for the prediction of crack development be derived. This model will then be able to predict the deterioration rate of pavement cracking in the future. It in turn will enable effective road rehabilitation programs be implemented in time before cracking deteriorates and leads to eventual pavement failure.
\end{abstract}

Keywords: Bitumen pavement cracks, Pavement failure, Crack prediction model

\section{INTRODUCTION}

Road pavements begin to deteriorate as soon as they are opened to the traffic and the design life is normally subjected to a period of 10 years time ${ }^{[12]}$. Normally, new paved roads deteriorate very slowly in the first ten or fifteen years of their life, and then go on to deteriorate much more rapidly unless timely maintenance is undertaken ${ }^{[8]}$. Bituminous surfacing tends to crack at some stage of their life under the combined actions of traffic and the environment through one or more different mechanisms.

The pavement crack is a defect in the bitumen surfacing which weakens the pavement and allows water to penetrate and cause further weakening. Cracking is characterized by two distinct phases. The initiation of cracking is defined as the appearance of the crack at the surface. Once initiated, cracking usually increases in its extent, severity and intensity, leading eventually to disintegration of the bitumen surface. Subsequently, cracking extends progressively over the surface and individual cracks widen.

Cracking therefore has long been an important criterion for maintenance purposes. The early detection and repair of defects such as cracks in pavements is one of the most important elements in road maintenance work. Cracks and other surface breaks, which in their early stages are almost unnoticeable, may develop and further deteriorate into serious defects if not attended to promptly.

The ability to predict cracking is dependent on several factors. Field data show strong effects of weathering, traffic and pavement design thickness. There is evidently an urgent need to develop a preliminary predictive performance model for cracking based on available data to derive the fundamental relationships between the components that define the problem, based on a reasonable set of assumptions, and upon which models relating design variables in a quantitative manner can be built.

\section{OBJECTIVE}

The objective of this study is to formulate a model that is able to predict the deterioration rate of a pavement cracking. This in turn would enable effective road rehabilitation programs to be implemented before cracking deteriorates the pavement and leads to its failure.

Early detection and repair of defects such as cracks in pavements are one of the most important elements in road maintenance work. Additionally, this model can be considered as a road management and planning tool for evaluating the allocation of funds, for estimating the timing and financial needs of the road maintenance and rehabilitation programs, and for planning and prioritizing the works in a program.

1 Student, Department of Civil Engineering, Faculty of Engineering, Universiti Malaysia Sarawak, Sarawak, Malaysia, jessweesingyi@yahoo.com. 2 Lecturer, Department of Civil Engineering,, Faculty of Engineering, Universiti Malaysia Sarawak, Sarawak, Malaysia, acron@feng.unimas.my

3 Student, Department of Civil Engineering, Faculty of Engineering, Universiti Malaysia Sarawak, Sarawak, Malaysia, rendezvous2020@hotmail.com 


\section{FACTORS AFFECTING PAVEMENT CRACKING}

A variety of factors such as traffic loading, specific standards of service and design, drainage, climate change risk factors, temperature, rainfall, and other atmospheric influences contribute to pavement deterioration, and in particular to pavement cracking, over the years.

Croney and Croney ${ }^{[2]}$ stated that deterioration of pavements arises from deformation under traffic loading generally associated with cracking and such deformation is often associated with heavy commercial vehicles. The increased loading will then cause failures such as cracks and depression on the pavement. According to the AASHTO Road Test, heavily loaded trucks can do more than 10,000 times the damage done by a normal passenger car.

Sargious ${ }^{[13]}$ highlighted the fact that one of the most important factors affecting pavement performance is climate. Both the pavement and the underlying supporting layers are exposed to strong climatic influences. Climate change here refers to any change in climate over time. Information extracted from global climate models suggests that the average temperatures and annual precipitation will increase over the next several decades with potential implications for pavement performance and design.

Climatic factors considered also include rainfall and annual variations in temperature. A review of pavement management practices, and engineering models and approaches used to monitor, assess and predict flexible pavement performance revealed that climate, and thus potential climate changes is an important consideration in the pavement deterioration processes ${ }^{[15]}$.

Rainfall has a significant influence on the stability and strength of the supporting pavement medium because it affects the moisture content of the sub grade and sub base. The effect of rain on road pavements can be destructive and detrimental as most pavements are designed based on a certain period of rainfall data. In addition, rainfall is well established as a factor affecting the elevation of the water table, the intensity of erosion, and pumping and infiltration. Long periods of rainfall of low intensity can be more adverse than short periods of high intensity because the amount of moisture absorbed by the soil is greater under the former conditions ${ }^{[13]}$.

Sargious ${ }^{[13]}$ further emphasised that water and poor drainage are the critical factors that cause road pavement failures. Once water has entered a road pavement, the damage initially is caused by hydraulic pressure. Vehicles passing over the road pavement impart considerable sudden pressure on the water, this pressure forces the water further into the road fabric and breaks it up. This process can be very rapid once it begins. When vehicles pass over the weak spot, the pavement will start to crack and soon the crack generate several cracks. Water will then enter the surface voids, cracks and failure areas. This can weaken the structural capacity of the pavement causing existing cracks to widen. Eventually, the water will descend to the subgrade below the road pavement, weakening and hence lowering the CBR value of the subgrade on which the road pavement design was based upon. Inadequate subgrade drainage will increase the severity and acceleration of the failures.

Climatic changes in temperature and rainfall patterns can interact together where higher temperatures increase cracking, which compounds the effects of increased rainfall. Climate change can have direct and indirect impacts on road infrastructure. The direct impacts predominantly are due to the effects of rainfall and temperature. Rainfall can alter moisture balances and influence pavement deterioration while the temperature changes can affect the aging of bitumen resulting in an increase in embrittlement of the surface chip seals. Embrittlement of the bitumen causes the surface to crack, with a consequent loss of waterproofing of the surface seal. The indirect impacts of climate change on roads are due to the effects on the location of population and human activity altering the demand for roads.

\section{METHODOLOGY}

This study is conducted to predict the road pavement deterioration rate with particular reference to cracking, by using available data from various agencies like the local Public Works Department, Drainage and Irrigation Department, Meteorological Department, local engineering consultant firms and road contractors.

The adopted methodology is as follows:

a. Identification of the proposed area of study 
b. Review of the behaviour, performance and deterioration of flexible pavements subjected to local climatic and traffic conditions

c. Collection of relevant data from local relevant government agencies, engineering consultant firms and road maintenance contractors through interviews and discussions

d. Comparison studies on the data obtained to create a model using Microsoft Excel software based on an assumed pavement cracking formula

e. Discuss appropriate solutions in rectifying pavement deficiencies with particular emphasis on cracks.

Traffic information and data are derived from traffic data published each year by the Highway Planning Unit of the Ministry of Works, Malaysia for census stations SR108 along Jalan Datuk Mohamad Musa. The published information consists of 16hour traffic census data including peak hour traffic volumes for the years 2000 till 2007. The traffic composition statistics are classified according to vehicle type. There is also information on the annual traffic growth rate and 16 hours traffic volumes for the years 2000 till 2007.

Rainfall data are procured from the Drainage and Irrigation Department at Kota Samarahan. The information consists of monthly and annual rainfall data for the years from 2000 to 2007. Air surface temperatures in the vicinities of the project areas in the Kota Samarahan region are extracted from the database of 8-year mean temperatures maintained by the Malaysian Meteorological Department, Kuching.

Subsequent data evaluation exercise will depend upon prediction of the rates at which roads will deteriorate. For this purpose, there is a need to derive a model of road deterioration which takes into account various factors such as traffic projections, specific standards of service and design, drainage, climate change risk factors, temperature, rainfall, and other atmospheric influences. However, due to unavailability of crack rating data from the relevant private and government agencies in Sarawak, hence it is not possible to derive a crack rating scale for road pavements.

As such and for purpose of comparison, typical values for this parameter are referred to those as highlighted in a Paper "Development of Flexible Pavement Performance Prediction Model Based on Pavement Data" presented by Kuo, Mahgoub, Hoffman and Kong ${ }^{[6]}$ at the Transportation Research Board $82^{\text {nd }}$ annual meeting held at Washington. It is therefore obvious that this particular prediction model although apparently suitable for use, cannot be verified accurately for the actual pavement conditions in Malaysia due to a lack of local pavement data.

\section{FORMULATION OF THE MODEL}

Pavement failure is a highly variable event which not only depends on layer material properties, environmental and sub grade condition and traffic loading, but also on the specific definition of failure adopted by the highway agency. Failure is usually defined in terms of amount of cracking, rut depth, surface roughness, skid resistance or combinations of these or other indicators of performance.

The development of cracking can be represented by two phases, namely the time before the initiation of cracking (or the age of the surfacing at first failure), and the rate of progression of the area of cracking. In addition, it is also represented by two severity levels, namely, all cracking (narrow and wide cracks more than $1 \mathrm{~mm}$ wide), and wide cracks (wider than $3 \mathrm{~mm}$ ). Predictions are also separated by major categories of surfacing and pavement type. In general, the prediction of cracking initiation has a probabilistic form, meaning a range of ages over which initiation is expected to occur.

The surfacing age at which cracking initiates was found to be strongly influenced by aging, traffic loading and pavement stiffness for all original surfacings. The rate of cracking progression was found to be fairly strongly non-linear, varying mainly with the cracked area. The deterioration models that need to be developed will need to take into account a broad variety of possible factors or parameters including climate, certain materials and types of pavement construction, and construction techniques.

In the particular area of study - Kota Samarahan, most pavement distresses are defined as cracking failure. The cracking classifications are described and illustrated in IKRAM's "A Guide to the Visual Assessment of Flexible Pavement Surface Conditions". Pavement cracks can be classified in three categories which are low severity, moderate severity and high severity. A crack rating scale of zero (0) to ten (10) can be proposed to cover these different levels of severity.

The formula adopted for use in this study is based on three main parameters namely crack rating, average daily traffic and slope degradation. However, the slope degradation parameter for pavement cracks could not be derived for the local conditions here. This is due to unavailability of crack rating data from the relevant private and government agencies in Sarawak. 

below:

It is proposed to adopt the pilot model used by Kuo, Mahgoub, Hoffman and Kong ${ }^{[6]}$ for a similar study which is as shown

$$
\begin{aligned}
& \text { Ycc = 0.979Ym } 1 c-0.8561 \times s \times\left(\frac{a}{10000}\right) \\
& \text { Where } \begin{array}{ll}
Y c c & =\text { last year's crack rating } \\
Y m l c & =\text { year before last year's cracking } \\
s & =\text { the slope of rating deterioration } \\
a & =\text { average daily traffic }
\end{array}
\end{aligned}
$$

The above formula was derived by Kuo, Mahgoub, Hoffman and Kong ${ }^{[6]}$ from a number of regression analysis iterations using various predictor variables, to finally obtain a good fitting equation. The predictor variables were restricted to last year's crack rating for the area under study, the slope or degradation over the past four years, and the annual average daily traffic. This formula has relevance to the local conditions here in Sarawak as it also shows a tendency for the next year cracking to decline, and the effect of heavier traffic should decrease the condition rating even more.

Assuming the pavement fails when the crack ratings falls to 6.0, the equation was solved for $n=$ the number of years until failure occurs when the pavement begins at a specified crack rating of $\mathrm{Y}(0)$. The solution using the new modified new formula is:

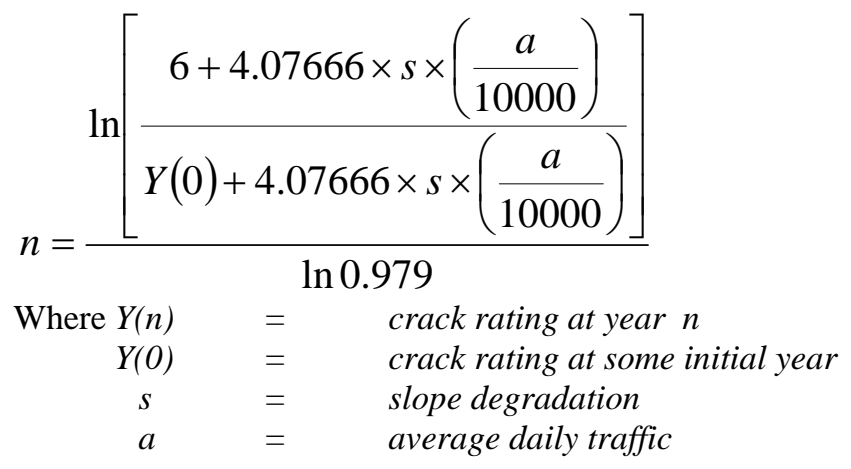

By varying $a, t$ and $\mathrm{Y}(0)$, the expected remaining lifetime of pavements could be obtained. The solution to this equation can be seen in graphical form in Figure 1. The predictions from this figure appear to be consistent with the expected behaviour. Firstly, it is noted that the range of expected remaining lifetimes for feasible values of $a$, $s$ and ratings is reasonable, ranging from lows near 1.0 more year to highs near 25 more years. Secondly, it is noted that as the average daily traffic increases, the expected lifetimes decrease and that larger historical rating degradations translate to lower expected remaining lifetimes. Additionally, if a segment of pavement has an initial crack rating which is greater than the other, then it is expected to last longer. 


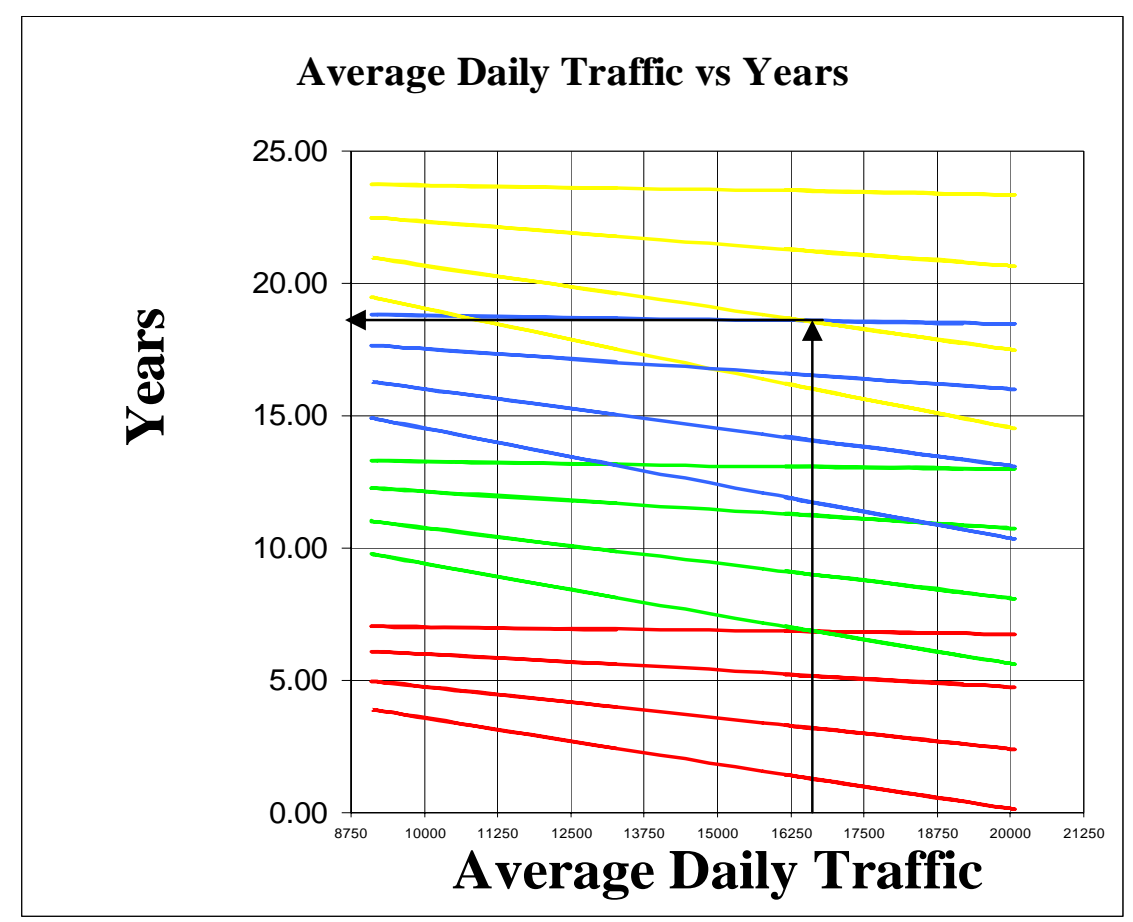

Figure 1: Expected Pavement Remaining Life: Kota Samarahan Crack Ratings

The figure above illustrates the average daily traffic vs years to determine the expected pavement remaining life for Kota Samarahan. The yellow line represents the current year of crack rating of ten (10), the blue line represents the current year of crack rating of nine (9), green line represents the current year of crack rating of eight (8) and red line represents the current year of crack rating of seven (7).

Within each color set, from top to bottom, the slope degradation runs from 0.1 to 0.5 to 1.0 and 1.5. Slope degradation is a comparative parameter which refers to the degree of deterioration of the crack rating value as it slowly deteriorates from a gentle slope to a steeper slope, thereby representing a worsening situation. This parameter is particularly important as crack rating is the main indicator of pavement failure in most cases.

\section{CONCLUSION}

It is strongly believed that the formulation of predictive models for the initiation of pavement cracking, including cracking progression, will significantly contribute to the successful implementation of road maintenance and rehabilitation programs, and also to the structural design of pavements. Such models could also serve as important validation sources and benchmarks for future design methods and road research ${ }^{[8]}$.

The preliminary establishment of a predictive model will therefore serve as a good aid towards predicting road deterioration rate for cracks for flexible pavement. It will help to plan road rehabilitation and maintenance more effectively, thus resulting in the increased performance level of road, cost saving to the maintenance authority and increase the level of comfort and safety of the road users.

However, this particular prediction model although apparently suitable for use, cannot be verified accurately for the actual pavement conditions in Malaysia due to lack of local pavement data. Local agencies should proceed with maintaining a database of pavement crack measurements and implement a crack rating system as part of road maintenance procedure. This will then help to facilitate the monitoring of pavement cracks as they appear, and enable crack repairs to be carried out periodically so as to enhance pavement's life 
UNIMAS E-Journal of Civil Engineering, Vol. 1: issue 1 /August 2009

\section{REFERENCES}

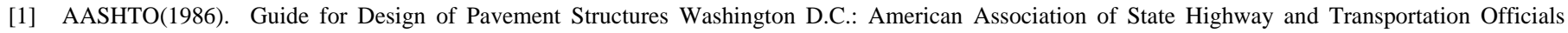
(AASHTO)

[2] Croney, P., \& Croney, D. (1998). The Design and Performance of Road Pavements. New York City: McGraw-Hill Professional

[3] Fwa, T.F. (2006). The Handbook of Highway Engineering. Boca Raton: Taylor \& Francis

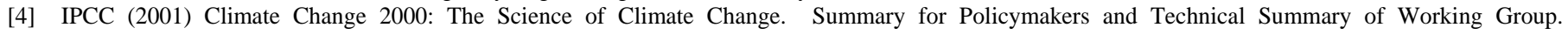
http://www.ipcc.ch/ 20 October 2008

[5] JKR \& IKRAM (1993). A Guide to the Visual Assessment of Flexible Pavement Surface Conditions. Kuala Lumpur: Jabatan Kerja Raya \& IKRAM

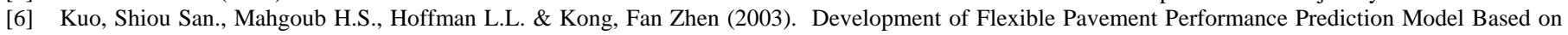
Pavement Data. Washington D.C.: Transportation Research Board

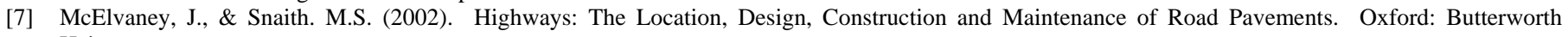
Heinemann

[8] Paterson, W. (1987). Road Deterioration and Maintenance Effects: Models for Planning and Management. Baltimore: The John Hopkins University Press

[9] Pavement Condition Rating System. http://training.ce.washington.edu/WSDOT/Modules/09_pavement_evaluation/09-6_body.htm/25 March 2009

[10] Pavement Surface Evualuation and Rating. http://epdfiles.engr.wisc.edu/pdf_web_files/tic/manuals/Concrete-PASERcontent_02.pdf/ 18 March 2009

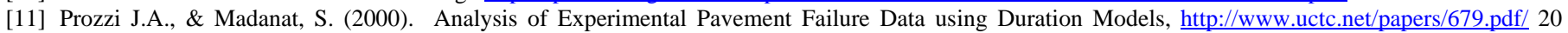
August, 2008

[12] REAM (1998). Guide to Evaluation and Rehabilitation of Flexible Road Pavements. Kuala Lumpur: Road Engineering Association of Malaysia (REAM)

[13] Sargious, M. (1975). Pavement and Surfacings for Highways and Airports. London: Applied Science Publishers Ltd

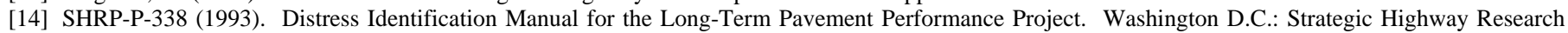
Program.

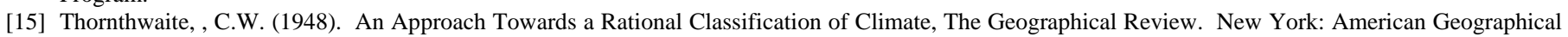
Society

[16] Walker, D., Entine, L. \& Krummer, S. (2001).Pavement Surface Evaluation and Rating (PASER). Wisconsin: Transportation Information Center 